\title{
Developing sustainability criteria for urban infrastructure systems ${ }^{1}$
}

\author{
Halla R. Sahely, Christopher A. Kennedy, and Barry J. Adams
}

\begin{abstract}
Research in the area of sustainable urban infrastructure reflects the need to design and manage engineering systems in light of both environmental and socioeconomic considerations. A principal challenge for the engineer is the development of practical tools for measuring and enhancing the sustainability of urban infrastructure over its life cycle. The present study develops such a framework for the sustainability assessment of urban infrastructure systems. The framework focuses on key interactions and feedback mechanisms between infrastructure and surrounding environmental, economic, and social systems. One way of understanding and quantifying these interacting effects is through the use of sustainability criteria and indicators. A generic set of sustainability criteria and subcriteria and system-specific indicators is put forward. Selected indicators are quantified in a case study of the urban water system of the City of Toronto, Ontario, Canada.
\end{abstract}

Key words: sustainable infrastructure, sustainability criteria and indicators, energy use, urban water systems.

\begin{abstract}
Résumé : La recherche dans le domaine des infrastructures urbaines durables reflète le besoin de concevoir et de gérer les systèmes d'ingénierie en tenant compte des aspects environnementaux et socioéconomiques. L'un des défis principaux pour l'ingénieur est de développer des outils pratiques afin de mesurer et d'améliorer la durabilité des infrastructures urbaines durant son cycle de vie. La présente étude développe un tel cadre pour l'évaluation de la durabilité des systèmes d'infrastructure urbaine. Le cadre porte principalement sur les interactions clés et les mécanismes de rétroaction entre l'infrastructure et les systèmes environnementaux, économiques et sociaux avoisinants. Une façon de comprendre et de quantifier ces effets interactifs et d'utiliser les critères et les indicateurs de durabilité est l'utilisation de critères et d'indicateurs de durabilité. Un ensemble générique de critères et de sous-critères de durabilité ainsi que des indicateurs spécifiques aux systèmes sont avancés. Les indicateurs choisis sont quantifiés dans une étude de cas du système d'aqueduc de la Ville de Toronto, Ontario, Canada.
\end{abstract}

Mots clés : infrastructure durable, critères et indicateurs de durabilité, utilisation de l'énergie, systèmes d'aqueduc urbains.

[Traduit par la Rédaction]

\section{Introduction}

Urban centres in North America and worldwide share a major and pressing problem: modern infrastructure, much of which was developed by the late 1960s, is showing serious signs of aging and deterioration. In addition, to exacerbate this situation, population growth in urban centres continues to increase. As a result, engineers are faced not only with the problems of infrastructure rehabilitation but also with an increased demand for infrastructure development. These challenges present themselves at a unique period of time in the

Received 17 March 2004. Revision accepted 4 August 2004. Published on the NRC Research Press Web site at http://cjce.nrc.ca on 8 March 2005.

H.R. Sahely, ${ }^{2}$ C.A. Kennedy, and B.J. Adams. Department of Civil Engineering, University of Toronto, 35 St. George Street, Toronto, ON M5S 1A4, Canada.

Written discussion of this article is welcomed and will be received by the Editor until 30 June 2005.

${ }^{1}$ This article is one of a selection of papers published in this Special Issue on Sustainable Development.

${ }^{2}$ Corresponding author (e-mail: h.sahely@utoronto.ca). history of civil engineering during which practitioners are embracing a new sustainability paradigm.

Over 10 years ago, the term sustainable development was coined and offered the world a new perspective on how to address the dilemma of advancing economic development while protecting environmental systems and enriching the quality of life for this and future generations (WCED 1987). The notion of sustainable development seeped into different disciplines. Its universality as a unifying and holistic paradigm appeals to many, and as a result the concept has been widely accepted. The main obstacle remains the transformation of principles of sustainable development into operational models.

Nowhere is this challenge more evident than in urban centres worldwide, where many regional and global environmental problems originate. Changes in the spatial distribution and structure of human activities have led to increased urbanization and its associated negative environmental impacts. At the heart of urban sustainability issues lie infrastructure systems. For the civil engineer, a major challenge is the development of practical tools to measure and enhance urban sustainability, especially through the design and management of infrastructure.

Research in the area of sustainable urban infrastructure must tackle this challenge. The main objective of this re- 
search is to develop quantitative frameworks for assessing the long-term sustainability of infrastructure relating to (i) decision-making, investment planning, and asset management; (ii) environmental factors (e.g., energy usage, materials inflows, and residuals); and (iii) efficient service provision to maintain and enhance quality of life.

One of the first steps in addressing these issues is the development of a set of sustainability criteria as part of a larger framework for the sustainability assessment of infrastructure systems. There is no doubt that sustainability considerations are inherently broad-based and interdisciplinary, and as a result there are several issues that need to be addressed to develop a practical set of sustainability criteria. The specific objectives of this paper are $(i)$ to review different approaches used for measuring sustainability and outline the principal research challenges; (ii) to outline a framework for understanding infrastructure sustainability in the light of environmental, economic, engineering, and social factors; (iii) to postulate sustainability criteria and indicators for infrastructure systems; and (iv) to quantify selected sustainability indicators for the urban water system of the City of Toronto, Ontario, Canada, as an illustrative example of the proposed framework.

\section{Measuring sustainability}

A good starting point in the discussion of sustainability criteria is the definition of sustainability. Even after years of discussion and debate, a precise definition has been elusive. In broad terms, sustainability implies the provision of more efficient services that maintain public health and welfare, are cost-effective, and reduce negative environmental impacts, today and into the future. A definition of sustainable development from an ASCE/UNESCO working group on developing sustainability criteria for water resources systems is put forth here as "... systems designed and managed to fully contribute to the objectives of society, now and in the future, while maintaining their ecological, environmental and [engineering] integrity" (ASCE/UNESCO 1998).

The overarching themes or key elements of any of the definitions proposed in the literature are $(i)$ proper assessment of relevant environmental, economic, and social factors; (ii) consideration of expanded temporal and spatial horizons; (iii) intergenerational equity; and (iv) the need for multidisciplinary considerations (Foxon et al. 2002; Rijsberman and van de Ven 2000; ASCE/UNESCO 1998).

Sustainable development is truly about achieving a balance between several objectives (environmental, economic, and social) over dynamic time and spatial horizons. Holism versus reductionism is advocated (Haimes 1992; Hellström et al. 2000). There is a need to consider temporal scales to expand options for action beyond the timeline of months and years to that of decades.

The notion of intergenerational equity translates into a need for systems to be adaptive given changing circumstances. As Loucks et al. (2000) note, there is no way of us knowing what future generations will want, and systems that can adapt to changing environmental or socioeconomic conditions are key. Consequently, Jeffrey et al. (1997) propose the design of adaptive, flexible, robust systems capable of supporting social and economic changes rather than locking communities into rigid spatial and temporal patterns.

Also implied by the sustainability paradigm is the need for multidisciplinary action and ensuring the appropriate stakeholders are involved in the decision-making process (Loucks et al. 2000; Margerum 1999).

An important aspect of this definition is the need to use a systematic approach to properly assess the impacts of engineering activities. Interdisciplinary research is crucial to better incorporate the sustainability paradigm into the complete life cycle of urban infrastructure. The term "engineering integrity" helps to focus on the quality of services provided by infrastructure and to ensure their continued efficient performance over time.

Sustainable development planning is an iterative, integrated process in which internal components within the system and also external interactions between the system in question (e.g., the urban water system) and other societal systems (e.g., financial and health systems) are considered. The field of engineering has much to offer to the discourse on sustainable development planning by contributing methodologies, algorithms, and tools for rational decision making under uncertain and dynamic circumstances (e.g., changing societal values, climate change).

One of many questions that has surfaced as a result of the discourse on urban sustainability is "How can we measure sustainability?" As a result, several types of measures of sustainability have been put forth. According to McLaren and Simonovic (1999), there exist two types of metrics for measuring sustainability, namely indicators and criteria.

\subsection{Indicators versus criteria}

Indicators are useful for monitoring and measuring the state of the environment by considering a manageable number of variables or characteristics (McLaren and Simonovic 1999). On the other hand, a sustainability criterion is the yardstick against which a sustainability indicator is measured (i.e., the goal or "ideal" condition in the relative comparison of indicators).

The main problem is relating what the indicators measure to actual sustainability. In other words, indicators are not useful when considered in isolation, but rather their usefulness comes from monitoring relative changes in the state of the environment. Indicators are not tell-all measures but rather proxy measures of the state of the environment and, in combination, of progress towards sustainability. Several studies at the urban, regional, and national levels have compiled extensive lists of sustainability indicators (Foxon et al. 2002; Hellström et al. 2000; Bossel 1999; Alberti 1996; Maclaren 1996).

Levett (1998) suggests that sustainability indicators have had mixed results in practice and, in some cases, minimal effects on policy. He notes that indicators are unavoidably value-laden, and it may be sometimes difficult to interpret whether or not any progress towards sustainability is actually being made. Levett concludes that only a few key indicators should be chosen and can evolve as policy and societal responses are evaluated.

As for sustainability criteria, many of the same disadvantages apply. In fact, the literature does not always distinguish between indicators and criteria, and the terms have been 
used interchangeably. Even though the setting of these goals or targets is no easy task, they provide stimuli to more thinking about precisely what a society values and how to integrate sustainability into engineering practice.

\subsection{Approaches to measuring sustainability}

In the engineering literature, the sustainability paradigm is generally viewed as a multiobjective optimization problem (Raval and Donnelly 2002; Balkema et al. 2002; Hellström et al. 2000; Haimes 1992). Different objectives can be to minimize capital and operating costs, energy use, land area, and waste production or to maximize useful products (such as biogas and clean water), recycling, overall performance, social acceptance, and accessibility. There is no doubt some objectives are conflicting and tradeoffs are often required.

Loucks (1997) describes a weighted multicriteria approach to quantifying trends in system sustainability with the following components: $(i)$ select various environmental, economic, and social indicators that contribute to sustainability; (ii) define satisfactory and unsatisfactory ranges of values for each indicator; (iii) collect data on indicators over time and express as a time series; (iv) analyze time series using statistical measures such as reliability (probability that any particular value will be within the range of values considered satisfactory), resilience (indicator of speed of recovery from an unsatisfactory condition), and vulnerability (statistical measure of the extent or duration of failure); and (v) calculate the relative sustainability of the system as a weighted combination of the aforementioned criteria, where relative sustainability is enhanced by an increase in the reliability and resilience, and a decrease in vulnerability.

Other criteria (step iv) that have been proposed are risk, reversibility, robustness, synergy, simplicity, functionality, adaptability, diversity, carrying capacity, and equity (McLaren and Simonovic 1999; Baetz and Korol 1995; Hashimoto et al. 1982). Loucks' (1997) method is one among many different "engineering" approaches to measuring the sustainability of infrastructure systems.

Haimes (1992) also suggests that the sustainability paradigm is a manifestation of a systems approach that is well supported by ample theory, methodologies, and problemsolving algorithms. One such methodology is life-cycle assessment.

Life-cycle assessment (LCA) is a structured methodology that can be utilized to evaluate the environmental implications of products, processes, projects, or services throughout their life cycles from raw materials extraction through endof-life (SETAC 1991; ISO 1997). The four components of LCA are goal and scope definition, inventory analysis, impact analysis, and improvement analysis. Goal and scope definition requires defining the purpose and scope of the study by defining system boundaries and establishing the functional unit to be considered. The inventory analysis is an accounting of the energy and raw materials use and discharges to all media over the entire life cycle of the product, material, process, project, or service. In practice, the impact analysis component of LCA categorizes the results from the inventory analysis into various environmental impact categories, such as depletion of resources and global warming potential. Lastly, improvement analysis is a systematic evaluation of the needs and opportunities to reduce the envi- ronmental burden associated with the life cycle of the product, material, process, project, or service. While LCA focuses mainly on environmental impacts, life-cycle costing (LCC) has emerged as an equivalent tool for examining economic impacts (Arditi and Messiha 1999; NIST 1996).

The main advantage of LCA is that it is a wellestablished, standardized methodology where potential impacts are aggregated and quantified. LCA has been used to assess the environmental impacts of residential homes (Keoleian et al. 2000) and various components of urban water systems (Lundie et al. 2004; Herz and Lipkow 2002; Friedrich 2002; Peters and Lundie 2002; Foxon et al. 2002; Lundin et al. 2000). LCA also has some major drawbacks, including the complex and time-consuming nature of the analysis, large data requirements, and boundary definition. Furthermore, LCA is mainly limited to environmental aspects and does not explicitly consider economic and social factors, which are important aspects of the sustainability paradigm. Nevertheless, the LCA methodology has contributed significantly to sustainability analysis by advocating expanded time and spatial boundaries in the analysis of systems.

\subsection{Principal challenges}

The conflicting goals faced by managers and engineers in the development and management of infrastructure systems is at the heart of why defining and implementing a sustainability strategy for such systems is difficult. Vanier (2001) categorizes these conflicting factors as follows: $(i)$ financial versus technical factors, (ii) short-term versus long-term planning horizons, and (iii) network versus project factors. The engineer, armed with shrinking financial resources, is consistently faced with the challenge of weighing the costs of maintenance, repair, or renewal versus technical performance. This is further exacerbated by considering different planning horizons and a variety of boundary issues. Infrastructure systems are integrated systems, and individual components must function both independently and, in most cases, synergistically with other systems (Vanier 2001).

With the advent of the sustainability paradigm, another conflicting goal is added to the list given previously. Increasing the sustainability of a system lies in the ability to balance various objectives. Tradeoffs are inevitable. The key, however, is to have a well-defined system and to utilize a systems approach in solving the objective function. The following sections propose a rational framework with which to view infrastructure systems in light of these conflicting goals and to aid in the selection of sustainability criteria and subcriteria (or indicators) to help measure progress towards sustainability.

\section{Sustainable infrastructure framework}

As outlined previously, engineers are faced with several complex issues in attempting to incorporate sustainability considerations into engineering design and management. To operationalize the sustainability paradigm, the engineer must adopt a systems approach and focus on a well-defined system to bring clarity to the larger debate on sustainability.

Figure 1 illustrates a generic framework put forward to help define the infrastructure system and understand its in- 
Fig. 1. Framework for assessing infrastructure systems.

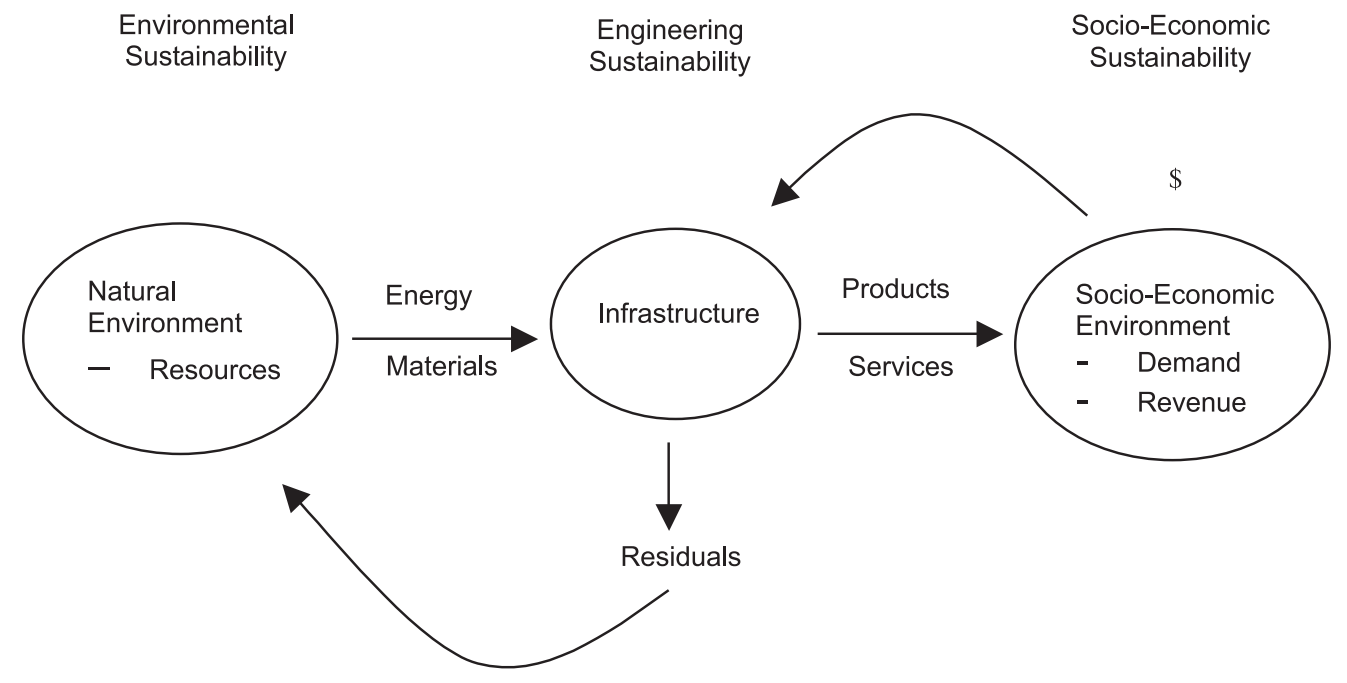

teraction with environmental, economic, and social systems. One of the engineer's main goals is to provide the best service possible using the least amount of resources. Therefore, when examining infrastructure systems, it is important to consider service provision efficiency per unit of physical resource input and dollar input. It is the job of the engineer to devise ways to "do more with less." This is consistent with the needs of the consumers who are not interested in physical units of energy or water but rather the services they provide and the cost of the services (Foxon et al. 1999). Any type of sustainability assessment developed for engineering systems needs to reflect this goal.

It is essential for the engineer to consider the feedback mechanisms inherent in the framework shown in Fig. 1 because they have important sustainability implications, both environmental and socioeconomic. For example, to promote more "sustainable" infrastructure, the revenues generated should be sufficient to cover the cost of operation and maintenance of the system, and ultimately the replacement cost. In addition, the energy and materials flow through the system and the residuals generated by the system should be minimized to the extent possible. Lastly, to continue to minimize impacts over time, additional investments in innovation and technology change are key; in this respect, adaptability and flexibility improve the efficiency of the system in the long term. An example of the framework applied to an urban water system is depicted in Fig. 2 and discussed further in the case study.

Application of the framework illustrated in Fig. 1 can be separated into three generic steps, based on LCA, to aid in the sustainability assessment of infrastructure systems. The three phases are (i) problem definition, (ii) inventory analysis (i.e., data collection and analysis), and (iii) impact assessment and decision analysis.

The crucial first step in this process includes definition of overall goals, system boundaries, and sustainability criteria and indicators. The goals of the sustainability assessment must be well defined. Typically, the purpose of such an analysis is to assess the system-wide sustainability impacts of potential changes (i.e., changes in technology, production, and (or) consumption patterns) on an infrastructure system.
Next, the system boundaries must be specified to incorporate extended temporal, spatial, and life-cycle perspectives. Lastly, sustainability criteria, subcriteria, and associated indicators must be selected to reflect the overall purpose of the analysis. A generic set of sustainability criteria is outlined in the next section.

\section{Sustainability criteria for infrastructure systems}

Sustainability criteria that characterize and account for the feedback mechanisms depicted in Fig. 1 are required to ensure that infrastructure systems are properly assessed within the analysis framework. In effect, the sustainability criteria and subsequent indicators are variables that are being monitored over time while engineers and decision-makers make changes to the system.

The proposed simple framework focuses on key interactions between infrastructure and environmental, economic, and social systems. As a result, sustainability criteria can be defined and follow naturally from the framework. The proposed set of criteria and generic subcriteria are categorized as follows: $(i)$ environmental, including resource use and residuals production; (ii) economic, including expenditures (capital, operation and maintenance) and investment in innovation; (iii) engineering, including performance; and (iv) social, including accessibility, acceptability, and health and safety.

Table 1 displays examples of system-specific subcriteria (or indicators) for various infrastructure systems. The goal is to maximize, minimize, or maintain a threshold level of the indicators listed previously. For example, Table 2 lists selected indicators specific to urban water systems and their relevance to overall environmental, economic, engineering, and social sustainability criteria. A more "sustainable" system, from an environmental standpoint, is one where resource use and residuals are minimized. On the other hand, socioeconomic criteria are met when costs are minimized while investment in research and development, technology change and innovation, accessibility, and health and safety are maintained at appropriate levels. Lastly, engineering or 
Fig. 2. Framework for assessing urban water systems. Solid lines represent water flows, and broken lines represent relevance to sustainability (adapted from Soares and Bernardes 2003).

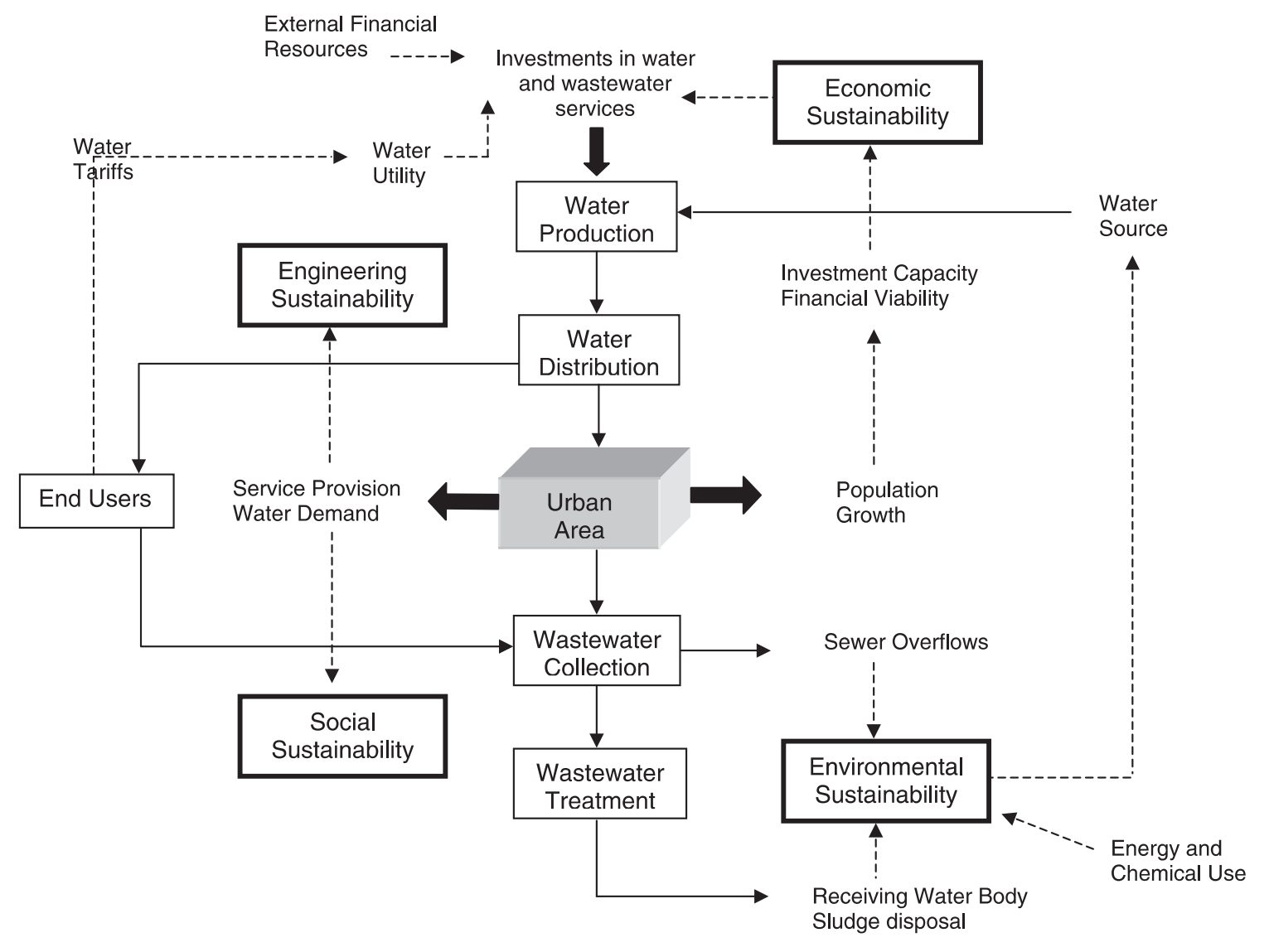

technical targets are achieved when performance is maximized or maintained at acceptable levels. Environmental, economic, and social indicators give insight into the efficiency of a system, whereas engineering or technical indicators determine the effectiveness of the system (Balkema et al. 2002). Sustainability indicators can be quantified using a variety of tools, including mass and energy balances, costbenefit analysis, and life-cycle costing, or characterized qualitatively.

Foxon et al. (2002) recommend five guiding principles in selecting indicators, appropriate for the system under consideration, from a set of generic criteria: (i) comprehensiveness, (ii) applicability, (iii) tractability, (iv) transparency, and (v) practicability. In their study of the water industry in the United Kingdom, Foxon et al. (2002) surveyed water service providers and ran focus groups with appropriate stakeholders to develop and incorporate sustainability criteria in the decision-making process. This type of study would be very useful for providers of urban infrastructure services in Canada to identify appropriate sustainability indicators and incorporate them into existing decision-making structures.

Another challenge is to determine what appropriate levels of each indicator are or whether or not the optimal (maximum or minimum) point has been reached. This determination is likely specific to local conditions; however, more research is needed to establish generic methodology for collecting, monitoring, and setting targets for indicators.

\subsection{Environmental criteria}

Most studies concerned with environmental sustainability agree on the nature of environmental indicators (Balkema et al. 2002; Lundin and Morrison 2002; Raval and Donnelly 2002; Foxon et al. 1999). These indicators are largely concerned with optimal resource utilization (e.g., use of water, nutrients, energy, and land) and minimal waste production (e.g., gaseous emissions, wastewater effluent, and solid waste).

Lundin and Morrison (2002) also describe various levels of environmental sustainability for urban water systems as follows:

(1) Level D - Basic objective of ensuring human and environmental health and adequate water supply are not met, and a minimum level of environmental monitoring occurs.

(2) Level $\mathrm{C}$ - Minimum standard for environmental protection and health objectives is met.

(3) Level B - Standards for environmental protection are met and exceeded, but still focused on compliance issues and end-of-pipe solutions. Regular monitoring of drinking water, storm water, and wastewater quality is in place.

(4) Level A - Environmental and health objectives are met. Efficient resource use and waste minimization practices including recycling of nutrients and water are in effect.

\subsection{Economic criteria}

Historically, decisions concerning the design, construction, maintenance, and improvement of infrastructure systems have been based largely on cost analysis and performance targets. 


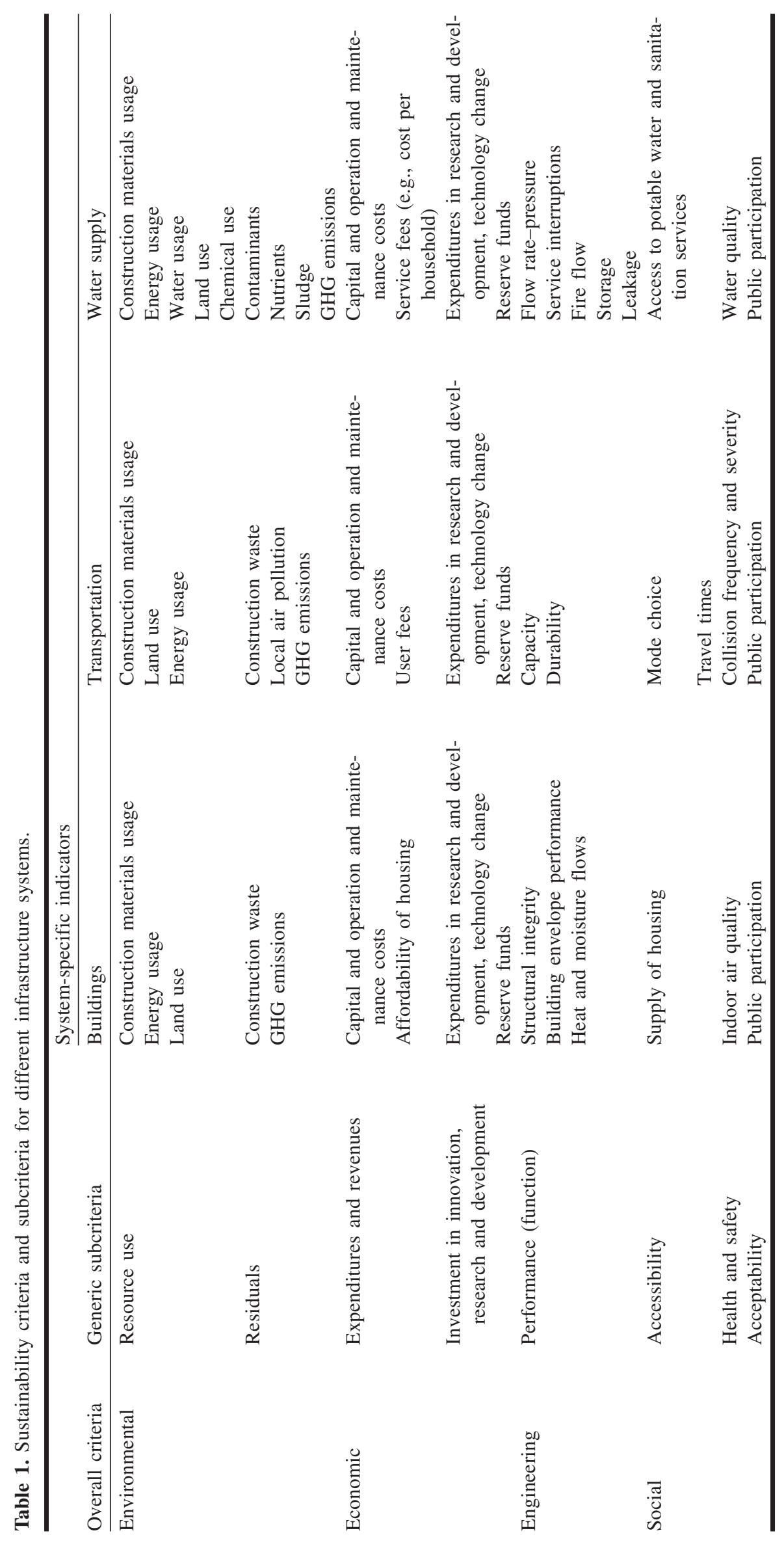




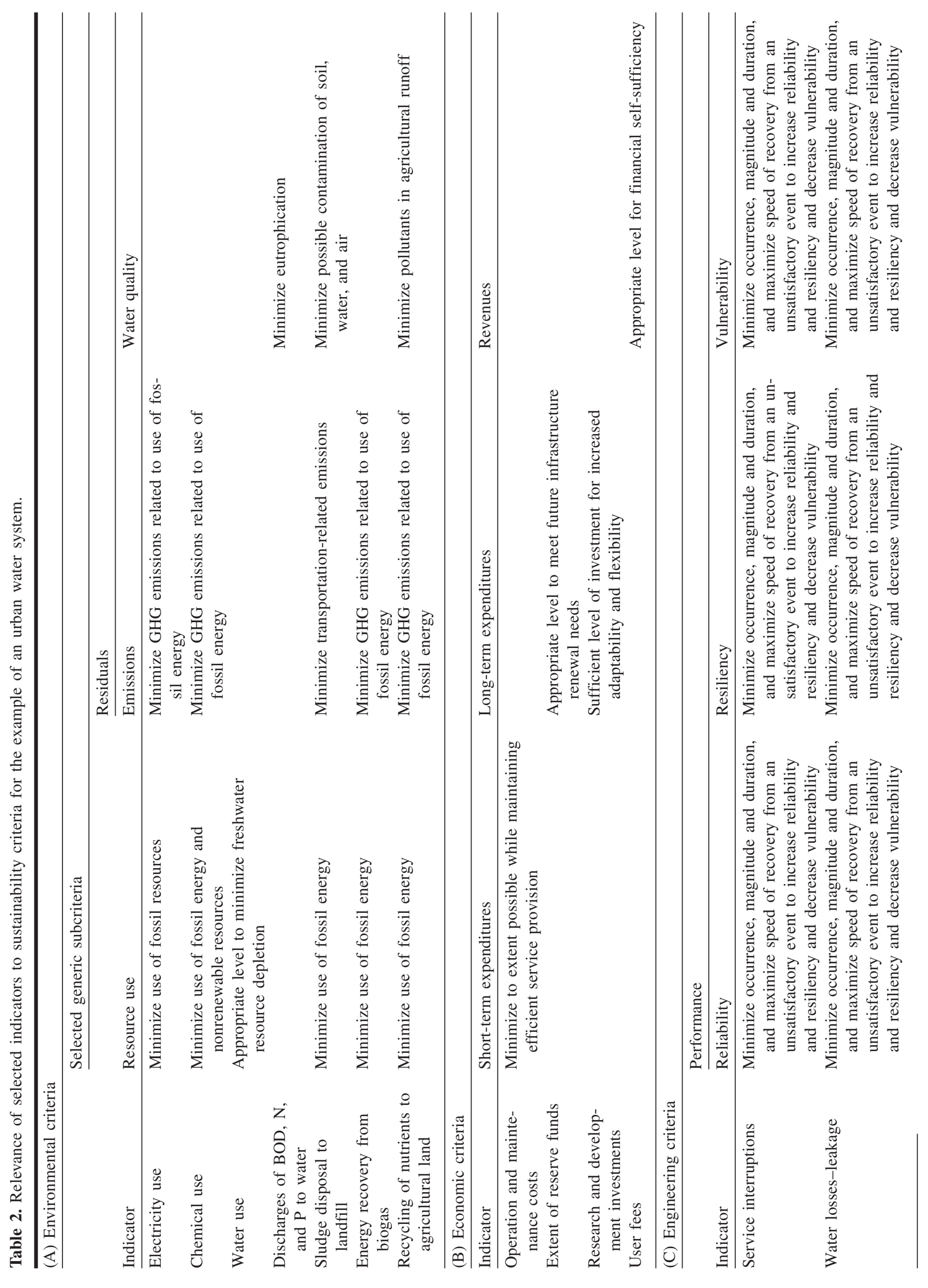


Today, economic indicators such as capital costs and operation and maintenance costs continue to play an important role in decision making as part of a larger set of indicators. Economic indicators need to be expanded, however, to include a measure of investment in research and development (i.e., innovation). Also, not unlike technical indicators that define the minimal technical requirements of a system, there is a need for a set of indicators to define and assess the minimal level of reserve funds required for effective asset management and timely infrastructure renewal.

\subsection{Engineering criteria}

A large set of engineering literature deals with measuring and assessing the performance of infrastructure systems. Hashimoto et al. (1982) discuss the use of reliability, resiliency, and vulnerability as criteria for the performance evaluation of water resource systems. ASCE/UNESCO (1998) also provide a comprehensive review of such performancebased criteria for water systems. Risk, reversibility, robustness, synergy, simplicity, functionality, adaptability, diversity, durability, and carrying capacity have also been put forward as additional engineering criteria.

\subsection{Social criteria}

Social and cultural criteria are much more difficult to quantify and as such have not received much attention in the engineering literature. Balkema et al. (2002) list awareness, participation, acceptance, institutional requirements, and responsibility among possible sociocultural indicators. Individually, engineers may not have the expertise to deal with social issues, but increasingly engineers are members of multidisciplinary teams charged with decision making regarding urban infrastructure. Such teams may deal with social issues appropriately.

\section{Case study: City of Toronto urban water system}

The use of sustainability criteria and indicators in infrastructure decision making is not practiced widely in Canada. The first part of this paper outlined the underlying principles of sustainability and how they may be translated and incorporated into infrastructure decision making using sustainability criteria. One of the main challenges in Canada is the collection and compilation of data at the urban level. Generally speaking, data collected at the urban level are scattered and fall under the jurisdiction of various departments of the local, provincial, and even federal governments. The first crucial step is to compile and synthesize data from these various sources into an integrated database (Sahely et al. 2003). This being said, a preliminary case study of the City of Toronto urban water system is presented as an example of the sustainable infrastructure framework outlined earlier. The case study is not meant as a comprehensive sustainability assessment of the City of Toronto urban water system but rather as an illustrative example of the process to quantify selected indicators. This preliminary analysis is part of a larger research project that aims to apply the framework (Fig. 1) in a quantitative manner for the sustainability assessment of the City of Toronto urban water system. 
On 1 January 1998, the regional municipality of Metro Toronto was amalgamated with the governments of the cities of East York, Etobicoke, Scarborough, York, and North York to form the new City of Toronto, with a population of almost 2.6 million covering an area of approximately $620 \mathrm{~km}^{2}$ (City of Toronto 2002). The City of Toronto Water and Wastewater Services Division is responsible for all aspects of the urban water system. White (2003) and Pharasi and Kennedy (2002) provide historic accounts of the development of the City of Toronto urban infrastructure systems.

The Water Supply Section of the Water and Wastewater Services Division treats, pumps, transmits, and stores potable water to supply all industrial, commercial, institutional, and residential water users in the city. The water supply infrastructure system includes four filtration plants (Clark, Harris, Horgan, and Island), 18 pumping stations, 10 major ground-level storage reservoirs, four elevated storage tanks, $471 \mathrm{~km}$ of trunk water mains, and over $5000 \mathrm{~km}$ of distribution mains (City of Toronto 2001). Water production at the four plants averaged $1488 \mathrm{ML} /$ day in 2001.

The wastewater collection, transportation, and treatment infrastructure includes four wastewater treatment plants (Ashbridges Bay, Humber, Highland Creek, and North Toronto), $4396 \mathrm{~km}$ of sanitary sewers, $1300 \mathrm{~km}$ of combined sewers, $4305 \mathrm{~km}$ of storm sewers, 74 sewerage pumping stations, and five wastewater storage and detention tanks (City of Toronto 2001). Approximately half of the average daily flow of $1302 \mathrm{ML} /$ day is treated at the Ashbridges Bay facility. The Water and Wastewater Operations and Water Pollution Control sections are responsible for issues related to operations, maintenance, and inspection of the wastewater system.

The City of Toronto water and wastewater pipes were laid to support growth cycles of the 1890s, 1920s, and 1950s as depicted in Fig. 3 (City of Toronto 2001; Gutteridge 2001). As a result, some of the water and wastewater infrastructure has been in service for more than 100 years. As of 2001, more than $7 \%$ of Toronto's water distribution system is older than 100 years, with an additional $13 \%$ between 80 and 100 years old (City of Toronto 2001).

Figure 4 shows total annual water consumption for the City of Toronto and per capita consumption from 1954 to 2001. Population growth was the main driver behind increased total annual water consumption until around 1990. The City of Toronto grew physically and demographically upwards from Lake Ontario after annexation of area municipalities began. A slight drop in water consumption in the early 1990s likely corresponds to an economic recession and a period of restructuring, which likely caused a decrease in industrial consumption. As Fig. 4 demonstrates, however, per capita consumption has not changed significantly in the past 50 years.

\subsection{Goal and system boundary definition}

The main objective of this case study is to investigate how the urban water system has changed over time and to assess the current situation with regard to selected sustainability indicators. Figure 2 represents the flow of water through the urban water system (including the water supply and wastewater systems) and depicts how environmental, economic, engineering, and social sustainability targets are related via driving forces such as population growth and water demand and the flow of water.

From an economic perspective, financial viability is a function of the water tariff structure that is based on water consumption, and consequently factors such as population growth and climate. Investment capacity is also related to the macroeconomic conditions within the urban area (Soares and Bernardes 2003).

Environmental sustainability targets are also closely tied to water consumption. For example, water filtration and wastewater treatment facilities involve processes that are energy and chemical intensive. Chemical and energy use contribute to the use of fossil fuel resources and related greenhouse gas (GHG) emissions. Direct and indirect (from energy-fuel use) emissions from Canadian wastewater treatment facilities have recently been quantified in a study by Sahely et al. ${ }^{3}$ Other environmental considerations including discharges of biochemical oxygen demand (BOD), nitrogen, and phosphorus can lead to eutrophication of receiving water bodies.

Driving factors such as water demand greatly influence the performance of the system. The efficiency of service provision is highly dependent on the state of the water and wastewater infrastructure, and ultimately on timely maintenance and renewal strategies.

The framework is dependent on the availability of reliable data to quantify indicators. According to Lundin and Morrison (2002), if a study is retrospective in nature, data collection for indicators should extend to at least 20 years, or as long as information is available. In this case, economic indicators were studied extensively as part of another project (Pharasi and Kennedy 2002), and data collection extended as far back as 60 years in some cases. Operational data such as energy and chemical use, however, are only available to the author for the last 2-5 years. Operational data have been collected and compiled in a more consistent fashion since amalgamation.

Given the illustrative nature of this case study, only selected environmental, economic, and engineering sustainability indicators are quantified and discussed. Data collection for social indicators is ongoing.

\subsection{Environmental indicators}

\subsubsection{Inputs: energy use}

Monthly electrical energy use data are available from 1999 to 2001 for three of the City of Toronto major wastewater treatment plants (Ashbridges Bay, Humber, and Highland Creek) as depicted in Fig. 5. Energy use has remained rather constant over this time period, consistent with the minor changes in treatment flow rates. The average electrical energy use per unit of wastewater treated for the three plants is $0.47 \mathrm{kWh} / \mathrm{m}^{3}$. This average falls within the range of values in the engineering literature, namely $0.41-0.55 \mathrm{kWh} / \mathrm{m}^{3}$ (Cheng 2002; Clauson-Kaas et al. 2001), and suggests the plants are not utilizing more energy than indicated by con-

\footnotetext{
${ }^{3}$ Sahely, H.R., MacLean, H.L, Monteith, H.D., and Bagley, D.M. Estimation of greenhouse gas emissions from Canadian municipal wastewater treatment plants. In preparation.
} 
Fig. 3. Historical time series of water and wastewater pipes installed (as percentage of total water main infrastructure) in the City of Toronto from 1870 to 1999 (Gutteridge 2001).

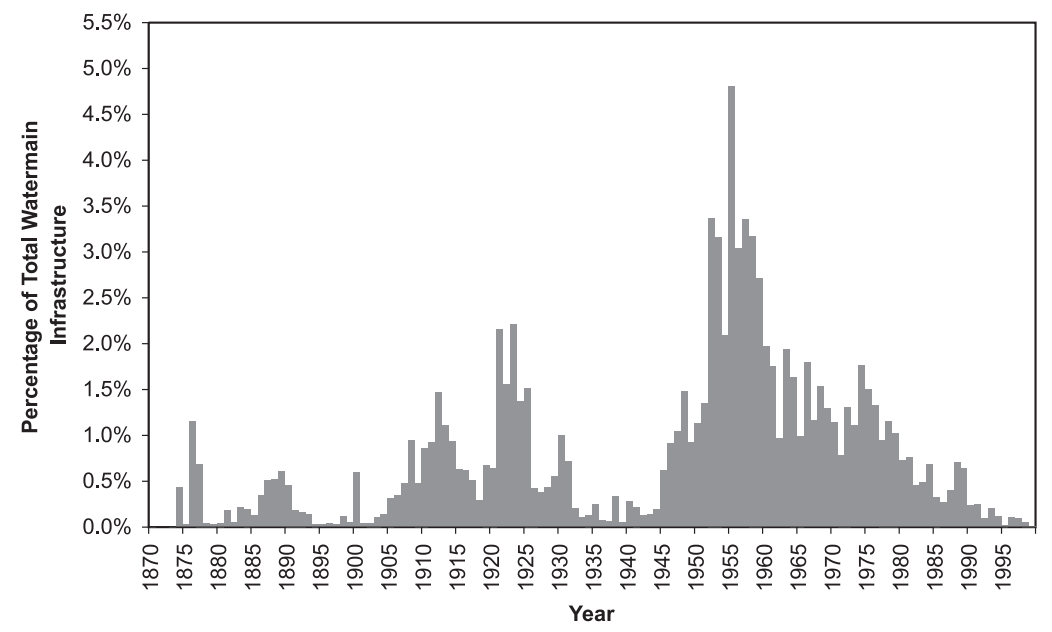

Fig. 4. Total and per capita water consumption rates for the City of Toronto from 1954 to 1996.

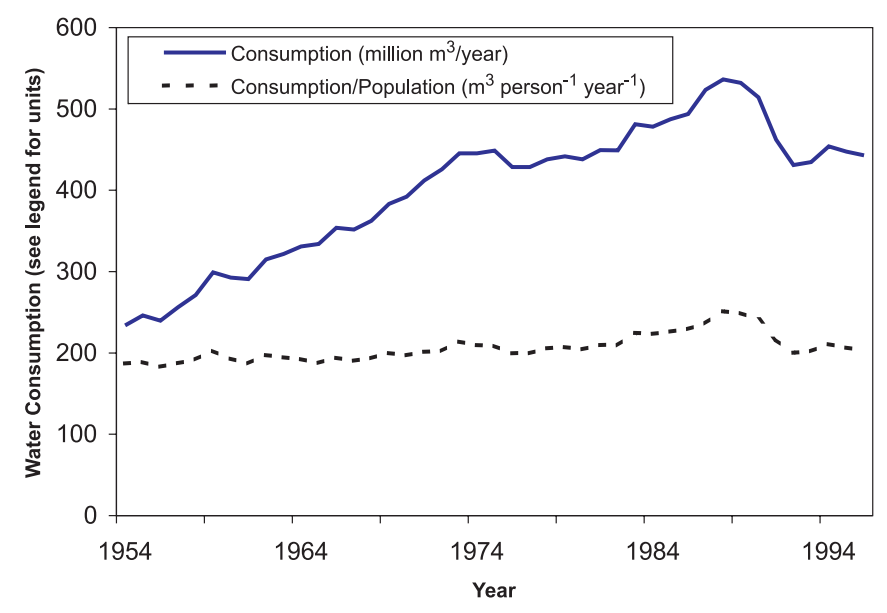

ventional practice. The wastewater treatment process has the potential to become a net producer of renewable energy, however, given the inherent energy potential of municipal wastewater. Shizas and Bagley (2004) found that the potential energy in raw municipal wastewater exceeds electricity requirements of the treatment process by a factor of 9.3 for a wastewater treatment plant in the City of Toronto. For example, methane-rich biogas produced as a result of anaerobic wastewater treatment processes is a potential source of renewable energy. At the present time, approximately $60 \%$ of biogas is combusted on site and used for heating purposes; the remaining biogas is flared, producing $\mathrm{CO}_{2}$. Opportunities for more effective energy recovery exist. Flaring recovers no energy, and heat recovery in boilers has no effect on electricity use. Cogeneration would provide much higher energy recovery overall, with both electricity and heat production.

Water distribution is the most energy intensive process in the urban water system. In 1999, average electrical energy use to operate pumps was on the order of $0.5-0.7 \mathrm{kWh} / \mathrm{m}^{3}$. During 1999, over $548 \mathrm{Mm}^{3}$ of water was pumped directly
Fig. 5. Total monthly electricity usage rates for the City of Toronto wastewater treatment plants from 1999 to 2001.

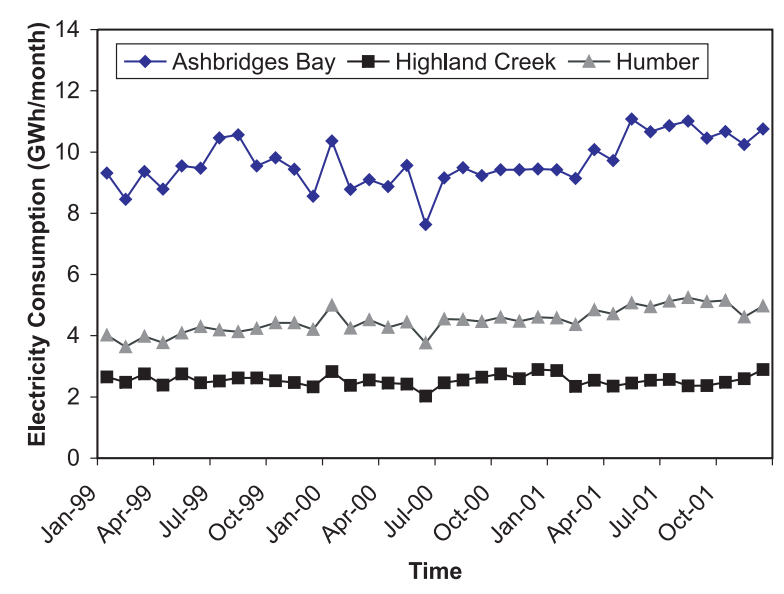

from filtration plants and associated pumping stations into the transmission system (City of Toronto 2000).

\subsubsection{Chemical use}

Various chemicals are utilized in the treatment of water and wastewater in the City of Toronto, whose water filtration facilities generally utilize alum for coagulation, chlorine for disinfection, sulphur dioxide for dechlorination, ammonia for ammoniation, and hydrofluosilicic acid for fluoridation. The wastewater treatment facilities utilize ferrous chloride for nutrient (phosphorus) removal, chlorine and sodium hypochlorite for disinfection and odor control, and various polymers for sludge thickening and dewatering. Monthly time series for chlorine are used as an example here.

Figures 6 and 7 outline chlorine use for three of the largest water (Clark, Harris, and Horgan) and wastewater (Ashbridges Bay, Humber, and Highland Creek) treatment plants, respectively. Monthly chlorine use data are available from 1999 to 2002. Chlorine use for water treatment exhibits a seasonal pattern, with peaks in the summer months. Typically, water consumption increases in the summer months and accounts for the associated pattern in chlorine 
Fig. 6. Total monthly chlorine usage rates for the City of Toronto water treatment plants from 1999 to 2002 (missing 2002 data from the Horgan and Harris plants).

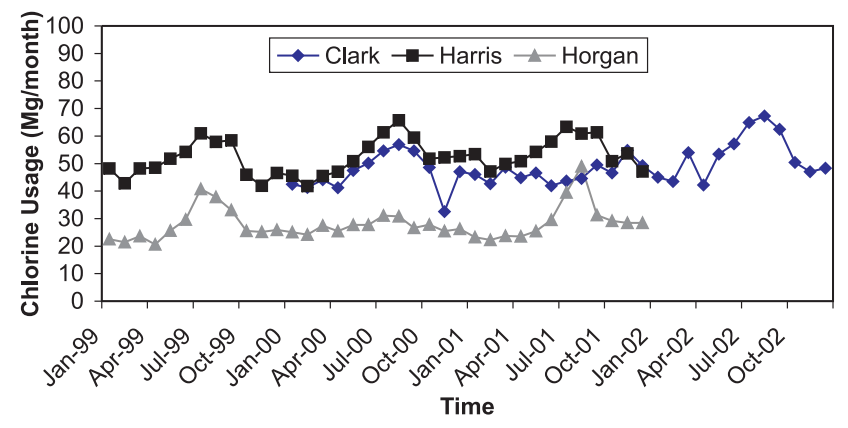

Fig. 7. Total monthly chlorine usage rates for the City of Toronto wastewater treatment plants from 1999 to 2001

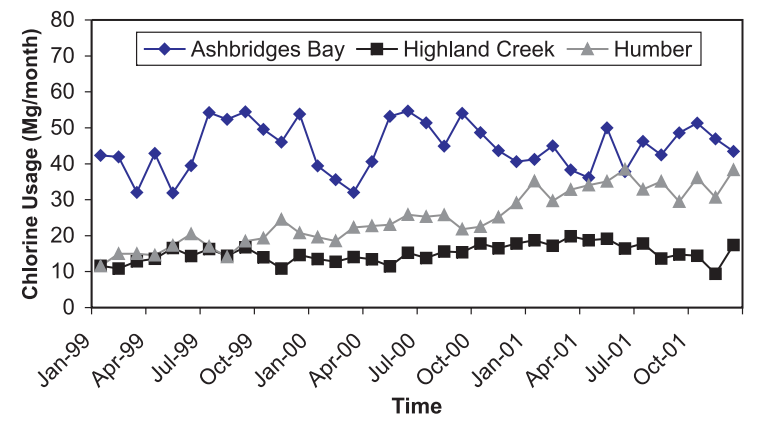

usage. In general, no increasing trend in chlorine use is evident. On the other hand, monthly chlorine usage for wastewater treatment exhibits a slightly increasing trend over the 3 year period.

\subsubsection{Residuals: GHG emissions}

Monteith et al. (2005) estimated the direct GHG emissions for Canadian wastewater treatment facilities. Detailed facility-specific estimates were also generated for 16 facilities including three in the Toronto area (Ashbridges Bay, Highland Creek, and North Toronto). Direct GHG emissions are defined as those produced on site at the wastewater treatment plant and are generated during liquid treatment, biosolids treatment, and biogas processing-combustion. A range of $290-640 \mathrm{~g} \mathrm{CO}_{2} / \mathrm{m}^{3}$ wastewater treated was estimated for the Toronto plants (Monteith et al. 2005).

Indirect GHG emissions from Canadian wastewater treatment facilities were further studied by Sahely et al. ${ }^{3}$ The two sources of indirect GHG emissions considered in the study were the off-site production and transmission of fuels and the off-site production of electricity that would be used on site. Sahely et al. ${ }^{3}$ estimated an emissions factor of $190 \mathrm{~g}$ $\mathrm{CO}_{2}$ equivalents/kWh for electricity generated in Ontario. Combined with an average electrical energy use of $0.47 \mathrm{kWh} / \mathrm{m}^{3}$ wastewater treated, indirect $\mathrm{GHG}$ emissions due to energy use are approximately $89 \mathrm{~g} \mathrm{CO}_{2}$ equivalents $/ \mathrm{m}^{3}$ wastewater treated at the City of Toronto wastewater treatment plants.

A similar emissions factor approach can be applied to measure the indirect emissions resulting from chemical use for water and wastewater treatment and is the focus of ongoing research.

\subsubsection{Discharges to receiving water}

Average wastewater effluent values for BOD, total suspended solids (TSS), and total phosphorus (TP) are shown in Table 3. Removal efficiency rates are high at $96 \%-97 \%$ for BOD, $87 \%-97 \%$ for TSS, and $82 \%-92 \%$ for TP. In general, the effluents meet overall discharge criteria set by the Ontario Ministry of the Environment (MOE), with the exception of TSS for the Highland Creek plant in the year 2000. In 2001, approximately $182 \mathrm{Mg}$ of biosolids were produced daily and either incinerated, landfilled, or applied to agricultural land. Eventually, the City of Toronto plans to recycle all of the biosolids generated at the Ashbridges Bay facility with its Biosolids Beneficial Use Program. Half of the biosolids generated will be pelletized and sold as fertilizer, and the remaining portion will be applied to agricultural land (City of Toronto 2001).

The problem of combined sewer overflows (CSOs) still remains in the City of Toronto. In 2000, the four wastewater treatment facilities reported approximately 55 bypass events totalling more than $4487000 \mathrm{~m}^{3}$. The City of Toronto has adopted several actions to alleviate this problem, including the separation of some sewers in the older parts of the city and the recent construction of the Western Beaches Tunnel and Eastern Storage Tanks to allow for storage and sedimentation of bypass volumes during large runoff events.

\subsection{Economic indicators}

\subsubsection{Expenditures on water infrastructure}

To compare changes in the capital and operational costs of water infrastructure over time, a method of reconciling population growth and price changes is required. For this case study, the ratio of infrastructure spending to total income (as an approximation for the City of Toronto GDP) was interpreted as the amount of investment in the water system in a given year, relative to its total capacity (Pharasi and Kennedy 2002). Figure 8 shows total capital expenditures and separate operational expenditures on water and sewers from 1935 to 1996. This figure highlights past trends in major investments and may shed light on how to increase economic sustainability in the future.

Figure 8 reveals a periodic rise in capital spending approximately every 20 years. There are peaks in 1937 (Harris water treatment plant), 1957 (extensive water main expansion), and 1977 (Humber wastewater treatment plant) that illustrate municipal spending on long-term capital projects. Such a peak did not occur in 1997 or from 1998 to 2000 (data not shown). Also, the relative operating costs of water supply have declined since 1935, following an approximately exponential function. Although there is some uncertainty in the data before 1957, the expenditure on operating the water system clearly declines from 1935 to 1955 . This increase in efficiency might be due to technological change (e.g., more efficient pumps), better management, or exploitation of economies of scale. The trend in sewer-wastewater treatment costs is quite different. Since 1955 there has been a general overall increase in the costs of sewer and wastewater operations, with particularly sharp rises in the late 
Table 3. Average daily wastewater discharge parameters at four wastewater treatment plants in the City of Toronto for the period 1999-2001 (City of Toronto 2000, 2001).

\begin{tabular}{|c|c|c|c|c|}
\hline \multirow[b]{2}{*}{ Year } & \multicolumn{4}{|c|}{ Effluent concentration $(\mathrm{mg} / \mathrm{L})$} \\
\hline & $\begin{array}{l}\text { Ashbridges } \\
\text { Bay }\end{array}$ & Humber & $\begin{array}{l}\text { Highland } \\
\text { Creek }\end{array}$ & $\begin{array}{l}\text { North } \\
\text { Toronto }\end{array}$ \\
\hline \multicolumn{5}{|c|}{ Biochemical oxygen demand ${ }^{a}$} \\
\hline 1999 & 4.0 & 5.0 & 6.0 & 3.4 \\
\hline 2000 & 5.0 & 6.0 & 8.0 & 4.3 \\
\hline 2001 & 5.0 & 6.0 & 9.0 & 4.3 \\
\hline \multicolumn{5}{|c|}{ Suspended solids $^{a}$} \\
\hline 1999 & 6.0 & 10.0 & 20.0 & 7.0 \\
\hline 2000 & 9.0 & 14.0 & 28.0 & 9.2 \\
\hline 2001 & 8.0 & 12.0 & 25.0 & 8.8 \\
\hline \multicolumn{5}{|c|}{ Phosphorus total $^{b}$} \\
\hline 1999 & 0.66 & 0.52 & 0.65 & 0.66 \\
\hline 2000 & 0.52 & 0.63 & 0.72 & 0.62 \\
\hline 2001 & 0.58 & 0.59 & 0.79 & 0.64 \\
\hline
\end{tabular}

${ }^{a}$ On annual average basis. Ontario Ministry of Environment (MOE) requirement is $25 \mathrm{mg} / \mathrm{L}$.

${ }^{b}$ On monthly average basis. MOE requirement is $1 \mathrm{mg} / \mathrm{L}$.

Fig. 8. Capital and operating expenditures for the City of Toronto water and sewer systems relative to total income of residents from 1935 to 1996.

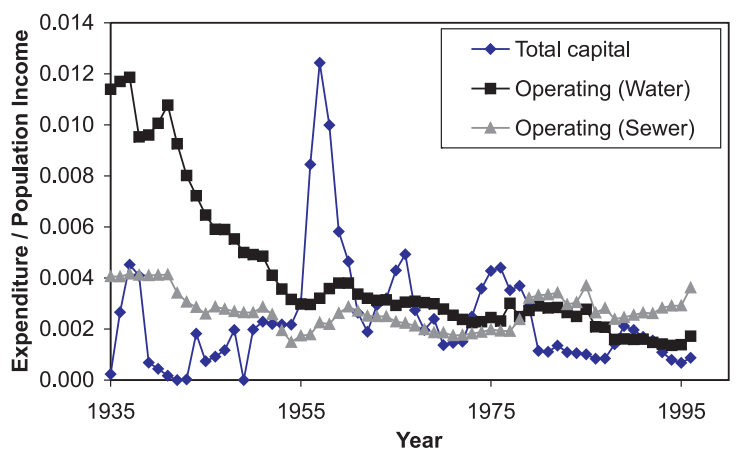

1950s and the 1980s. These increased costs are likely attributed to more stringent standards since 1970, the sewer separation program in place since 1975, the energy-intensive nature of current wastewater treatment technology, and the construction of wet-weather flow control facilities since 1990.

Overall, there are clearly two peaks in 1937 and 1957, at which total expenditures (sum of all three lines in Fig. 8) reached close to $2 \%$ of the overall income of city residents. Since 1957 there has been a general decline in expenditures. Some understanding of these trends follows from Fig. 8, although a complete explanation requires further research. This being said, random effects such as extreme weather events can also influence total costs and are only expected to increase in light of global climate change.

\subsection{Engineering indicators}

\subsubsection{Number of detected leaks in water distribution system}

Figure 9 shows an increasing trend in the number of leaks detected in the City of Toronto water distribution system be-
Fig. 9. Number of detected leaks for the City of Toronto water distribution system from 1968 to 1994.

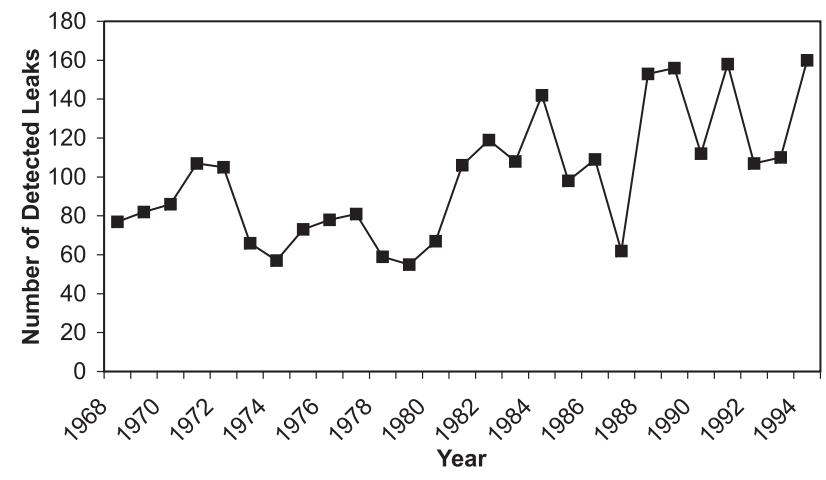

tween 1968 and 1994. Approximately 25\% of the entire system is inspected on an annual basis. The aging pipe infrastructure in Toronto is likely the main driving force behind the upward trend in leaks. In 2001, more than $7 \%$ of the City of Toronto water distribution system was older than 100 years, with an additional 13\% between 80 and 100 years old (City of Toronto 2001).

The presence of leaks increases operating costs as a result of water loss and extra energy consumption and treatment costs. Although concern over leaks has been typically related to lost revenues due to lost water, there is also a connection between leaks and energy wastage because pumps must work harder to maintain the same level of service (Colombo and Karney 2002). Such energy wastage also has environmental implications due to resource depletion, greenhouse gas emissions, engineering implications concerning the timing of maintenance, and capacity expansion activities and economic concerns due to lost revenues and increased operational costs (Colombo and Karney 2002).

\section{Discussion}

The indicators quantified previously offer a glimpse into the state of the City of Toronto urban water system and its progress towards sustainability. Taking a closer look at the set of environmental indicators quantified in Sect. 5.2 and the levels of environmental sustainability devised by Lundin and Morrison (2002) and summarized in Sect. 4.1, the City of Toronto seems to fall within level B of environmental sustainability based on the key assumption that current environmental standards and energy and chemical norms are sustainable. This assumption is weakened by the fact that current norms were not originally constructed with sustainability principles in mind. For example, current energy and chemical norms utilize significant nonrenewable fossil resources. Additionally, as noted earlier, there is much room for improvement in terms of water and energy efficiency for the City of Toronto urban water system, especially in the case of the untapped energy potential of wastewater. This being said, the City of Toronto has taken progressive steps to manage biosolids in a more sustainable manner and to increase water efficiency as outlined in its Water efficiency plan (City of Toronto 2002).

As for the economic indicators quantified, the rising costs in sewer and wastewater operations raise some questions that require further research. Does the City of Toronto sewer in- 
frastructure exhibit decreasing economies of scale? Have the goals of operation been chasing an illusive trail of diminishing returns? Has the influx of new technology not played a role in reducing costs per capita? The answers to these questions cannot be gleaned from looking at costs alone. By casting a wider net around the urban water system and utilizing a systems approach, factors that influence infrastructure systems can be better understood and incorporated into day-today decision making.

Overall, the framework outlined in Figs. 1 and 2 and the list of sustainability criteria, subcriteria, and indicators (Table 1) and their relevance to sustainability (Table 2) offer a roadmap for future sustainability assessments. Adopting a systems approach and considering the urban water system as a whole offer many advantages for decision makers. It can be seen how changes to one part of the system can have various system-wide impacts. In the case of an urban water system, for example, the repair of old leaky pipes has several positive impacts beyond just saving lost water. These benefits include saving energy and reducing associated GHG emissions and operational costs as well as increasing effective performance of the system and the level of service to consumers.

This type of cascading, system-wide impact is evident throughout the urban water system if a holistic approach is used and environmental, economic, engineering, and social implications of decisions are considered. Such system complexity highlights the need for rational impact and decision analysis once the system is sufficiently characterized using sustainability criteria and indicators. More research is needed to identify decisive indicators (i.e., those indicators which influence the outcome of the sustainability assessment), to analyze the trade-offs and sensitivity to weighting factors (Balkema et al. 2002).

\section{Summary and conclusions}

A framework is developed for the sustainability assessment of urban infrastructure systems which focuses on key interactions and feedback mechanisms between infrastructure and surrounding environmental, economic, and social systems. Three generic steps are defined from the framework: (i) problem definition, (ii) inventory analysis (i.e., data collection and analysis), and (iii) impact assessment and decision analysis.

The first step is crucial and includes the definition of goals, system boundaries, and sustainability criteria and indicators. The proposed sustainability criteria reflect the various dimensions of sustainability, namely, environmental, economic, engineering, and social. The associated subcriteria are (i) resource efficiency and residuals production; (ii) expenditures and investment in innovation and infrastructure renewal; (iii) performance; and (iv) accessibility, acceptability, and health and safety. A variety of indicators can be defined that reflect the infrastructure system being analyzed and regional and local conditions. The City of Toronto urban water system is used as an illustrative example of the process of selecting and quantifying relevant indicators (i.e., inventory analysis).

Sustainable urban infrastructure research needs to focus on developing rational methodologies for impact and deci- sion analyses. Notwithstanding the somewhat subjective nature of impact analysis, the engineer can contribute to more rational decision making by analyzing decisive indicators, trade-offs, and weighting sensitivities. Lastly, the framework and associated tools should be integrated into a decision support tool for urban infrastructure. This will promote interdisciplinary research and more comprehensive, multisectoral, multipurpose, and multiobjective studies related to sustainable urban infrastructure.

\section{Acknowledgements}

The authors wish to gratefully acknowledge the support for this work by the Natural Sciences and Engineering Research Council (NSERC) of Canada.

\section{References}

Alberti, M. 1996. Measuring urban sustainability. Environmental Impact Assessment Review, 16: 381-424.

Arditi, D., and Messiha, H.M. 1999. Life cycle cost analysis (LCCA) in municipal organizations. Journal of Infrastructure Systems, 5(1): 1-10.

ASCE/UNESCO. 1998. Sustainability criteria for water resource systems. American Society of Civil Engineers (ASCE), Task Committee on Sustainability Criteria and Working Group of UNESCO/IHP-IV Project M-4.3. American Society of Civil Engineers, Reston, Va.

Baetz, B.W., and Korol, R.M. 1995. Evaluating technical alternatives on the basis of sustainability. Journal of Professional Issues in Engineering Education and Practice, 121(2): 102-107.

Balkema, A.J., Preisig, H.A., Otterpohl, R., and Lambert, F.J.D. 2002. Indicators for the sustainability assessment of wastewater systems. Urban Water, 4: 153-161.

Bossel, H. 1999. Indicators for sustainable development: theory, method, applications. International Institute for Sustainable Development, Winnipeg, Man.

Cheng, C.-L. 2002. Study of the inter-relationship between water use and energy conservation for a building. Energy and Buildings, 34: 261-266.

City of Toronto. 2000. Water ... Toronto treats it with care: Water and Wastewater Services Division review 1999/2000. Water and Wastewater Services Division, Water Pollution Control, Works and Emergency Services Department, City of Toronto, Toronto, Ont.

City of Toronto. 2001. The water cycle: from the lake to you and back again: Water and Wastewater Services Division review 2000/2001. Water and Wastewater Services Division, Water Pollution Control, Works and Emergency Services Department, City of Toronto, Toronto, Ont.

City of Toronto. 2002. Water efficiency plan. Works and Emergency Services Department, City of Toronto, Toronto, Ont.

Clauson-Kaas, J., Poulsen, T.S., Jacobsen, B.N., Guildal, T., and Wenzel, H. 2001. Environmental accounting - a decision support tool in WWTP operation and management. Water Science and Technology, 44(2-3): 25-30.

Colombo, A.F., and Karney, B.W. 2002. Energy and costs of leaky pipes: towards a comprehensive picture. Journal of Water Resources Planning and Management, 128(6): 441-450.

Foxon, T.J., Leach, M., Butler, D., Dawes, J., Hutchinson, D., Pearson, P., and Rose, D. 1999. Useful indicators of urban sustainability: some methodological issues. Local Environment, 4(2): 137-149. 
Foxon, T.J., Butler, D., Dawes, J.K., Hutchinson, D., Leach, M.A., Pearson, P.J.G., and Rose, D. 2000. An assessment of water demand management options from a systems approach. Journal of the Chartered Institution for Water and Environmental Management, 14: 171-178.

Foxon, T.J., McIlkenny, G., Gilmour, D., Oltean-Dumbrava, C., Souter, N., Ashley, R., Butler, D., Pearson, P., Jowitt, P., and Moir, J. 2002. Sustainability criteria for decision support in the UK water industry. Journal of Environmental Planning and Management, 45(2): 285-301.

Friedrich, E. 2002. Life cycle assessment as an environmental management tool in the production of potable water. Water Science and Technology, 46(9): 29-36.

Gutteridge, B.H. 2001. Water and wastewater services long-term sewer and water main infrastructure renewal needs. Staff Report, City of Toronto, Toronto, Ont.

Haimes, Y.Y. 1992. Sustainable development: a holistic approach to natural resource management. IEEE Transactions on Systems, Man, and Cybernetics, 22(3): 413-417.

Hashimoto, T., Stedinger, J.R., and Loucks, D.P. 1982. Reliability, resiliency and vulnerability criteria for water resource system performance evaluation. Water Resources, 18(1): 14-20.

Hellström, D., Jeppsson, U., and Kärrman, E. 2000. A framework for systems analysis of sustainable urban water management. Environmental Impact Assessment Review, 20: 311-321.

Herz, R.K., and Lipkow, A. 2002. Life cycle assessment of water mains and sewers. Water Science and Technology: Water Supply, 2(4): 51-72.

ISO. 1997. Environmental management - life cycle assessment principles and framework (ISO 14040). International Organization for Standardization (ISO), Geneva, Switzerland.

Jeffrey, P., Seaton, R., Parsons, S., and Stephenson, T. 1997. Evaluation methods for the design of adaptive water supply systems in urban environments. Water Science and Technology, 35(9): 41-51.

Keoleian, G.A., Blanchard, S., and Reppe, P. 2000. Life-cycle energy, costs, and strategies for improving a single-family house. Journal of Industrial Ecology, 4(2): 135-156.

Levett, R. 1998. Sustainability indicators - integrating quality of life and environmental protection. Journal of the Royal Statistical Society A, 161(3): 406-410.

Loucks, D.P. 1997. Quantifying trends in system sustainability. Hydrological Sciences Journal, 42(4): 513-530.

Loucks, D.P., Stakhiv, E.Z., and Martin, L.R. 2000. Sustainable water resources management. Journal of Water Resources Planning and Management, 126(2): 43-47.

Lundie, S., Peters, G.M., and Beavis, P.C. 2004. Life cycle assessment for sustainable metropolitan water systems planning. Environmental Science and Technology, 38: 3465-3473.

Lundin, M., and Morrison, G.M. 2002. A life cycle assessment based procedure for development of environmental sustainability indicators for urban water systems. Urban Water, 4: 145-152.

Lundin, M., Bengtsson, M., and Molander, S. 2000. Life cycle assessment of wastewater systems: influence of system boundaries and scale on calculated environmental loads. Environmental Science and Technology, 34: 180-186.
Maclaren, V. 1996. Developing indicators of urban sustainability: a focus on the Canadian experience. Intergovernmental Committee on Urban and Regional Research (ICURR) Press, Toronto, Ont.

Margerum, R.D. 1999. Integrated environmental management: the foundations for successful practice. Environmental Management, 24(2): 151-166.

McLaren, R.A., and Simonovic, S.P. 1999. Data needs for sustainable decision making. International Journal of Sustainable Development and World Ecology, 6: 103-113.

Monteith, H.D., Sahely, H.R., MacLean, H.L., and Bagley, D.M. 2005. A rational procedure for estimation of greenhouse gas emissions from municipal wastewater treatment plants. Water Environment Research. 77(3).

NIST. 1996. Life cycle costing manual for the federal energy management program. 1996 ed. NIST Handbook 135, National Institute of Standards and Technology (NIST), Washington, D.C.

Peters, G., and Lundie, P. 2002. Life-cycle assessment of biosolids processing options. Journal of Industrial Ecology, 5(2): 103-121.

Pharasi, S., and Kennedy, C.A. 2002. Reflections on the financial history of Toronto's urban water infrastructure. In Proceedings of the 30th Canadian Society for Civil Engineering Annual Conference, Montréal, Que., 5-8 June 2002. Edited by M.-J. Nollet and M. Trepanier. Canadian Society for Civil Engineering, Montréal, Que. Paper GE062, pp. 1-10.

Raval, P., and Donnelly, T. 2002. Multi-criteria decision making for wastewater systems using sustainability as a criterion. In Proceedings of the Joint ASCE-EWRI Water Resources Planning and Management Conference, Roanoke, Va., 19-22 May 2002. ASCE, New York. pp. 1-10.

Rijsberman, M.A., and van de Ven, F.H.M. 2000. Different approaches to assessment of design and management of sustainable urban water systems. Environmental Impact Assessment Review, 20: 333-345.

Sahely, H.R., Dudding, S., and Kennedy, C.A. 2003. Estimating the urban metabolism of Canadian cities: Greater Toronto Area case study. Canadian Journal of Civil Engineering, 30: 468-483.

SETAC. 1991. A technological framework for life cycle assessment. Society of Environmental Toxicology and Chemistry (SETAC), Washington, D.C.

Shizas, I., and Bagley, D.M. 2004. Experimental determination of the energy content of unknown organics in municipal wastewater streams. Journal of Energy Engineering, 130(2): 45-53.

Soares, S.R.A., and Bernardes, R.S. 2003. Water supply and sanitation planning model: management tool for Brazilian cities. Water Science and Technology: Water Supply, 3(1-2): 469-476.

Vanier, D.J. 2001. Why industry needs asset management tools. Journal of Computing in Civil Engineering, 15(1): 35-43.

WCED. 1987. Our common future. World Commission on Environment and Development (WCED), Oxford University Press, Oxford, U.K.

White, R. 2003. Urban infrastructure and urban growth in the Toronto region 1950s to the 1990s. Neptis Foundation, Toronto, Ont. 